\title{
IONOSPHERIC VARIATIONS OVER INDIAN LOW LATITUDES
}

\author{
Dr.A.Mahesh Kumar \\ Department of Physics, Government Degree College, Armoor, Nizamabad, Telangana, India
}

\begin{abstract}
Ionosphere is being used by numerous communication systems to reflect radio signals over long distances. The critical frequency (foF2) is the preventive frequency at or lower which a radio wave is reflected by ionosphere in $\mathrm{HF}$ radio propagation. The atmosphere can be divided vertically into zones based on changes that occur with altitude as Troposphere, Stratosphere, Mesosphere, Ionosphere and Thermosphere. The Earth's ionosphere exhibits complex variabilities with varying spatial and temporal scales. The ionosphere is also restricted by the solar zenith angle, manifesting diurnal, annual and semiannual variations. In the low latitudes, the thermospheric wind and electric field, in conjunction with Earth's magnetic field, play an important role in the redistribution of plasma. With regard to the low-latitude ionosphere, variabilities in the F- region have been given special attention due to their direct effects on communication / navigation systems. A large number of observational and modeling studies have been made to understand $\mathrm{F}$ region parameters, such as the critical frequency of the F2 layer, foF2 and the corresponding height, $\mathrm{hmF} 2$, in terms of variabilities in solar flux, magnetic field, neutral dynamical/ electro dynamical parameters.
\end{abstract}

Key Words-- Ionospheric Variations, Critical frequency, FoF2 and hmF2, Solar ionizing flux, low-latitude, Ionospheric parameters, Troposphere, Stratosphere, Mesosphere, Ionosphere, Thermosphere.

\section{INTRODUCTION}

The ionosphere is that layer of the Earth's atmosphere which extends from 80 to $1000 \mathrm{Km}$. It affects the propagation of radio waves significantly. Ionosphere is being used by loads of communication systems to reflect radio signals over lengthy distances. The ionosphere can reflect waves of frequencies below about $30 \mathrm{MHz}$, allowing (HF) radio communication to distances of many thousands of kilometers. The critical frequency (foF2) is the limiting frequency at or below which a radio wave is reflected by ionosphere in HF radio propagation. If the frequency is higher than this value the wave penetrates through an ionosphere F-layer. For long distance high frequency communication F2-region plays important role in the ionosphere because of its thickness and minimal attenuation for probing radio waves.

Variations in the critical frequency afford intimations on the occurrences within the F2-layer. Surveillances show that after sunrise foF2 rises, reaches to its greatest value in the early afternoon, and there is a quick fall shortly after sunset. This layer of the ionosphere is affected by numerous influences such as solar wind, solar ionizing radiation, neutral atmosphere, geomagnetic activity and electrodynamics effects. (Rishbeth and Mendillo, 2001) Various authors have examined ionospheric variability. Number of studies has been done for investigating the variability of the ionosphere

\section{VERTICAL STRUCTURE OF THE ATMOSPHERE}

The atmosphere can be divided vertically into zones based on changes that occur with altitude.

\subsection{TROPOSPHERE}

The lowest part of the atmosphere known as the troposphere forms a natural lid on the lower atmosphere in which the temperature decreases with altitude. A distinct boundary layer known as the tropopause marks the upper reaches of the troposphere and the upper limit of most turbulent mixing started from the surface. At the equator the tropopause is at a height of $16-17 \mathrm{~km}$.

\subsection{STRATOSPHERE}

Above the tropopause is the stratosphere, which is named for the layered nature of the air at these levels. The stratosphere is relatively stable, dry and has little vertical motion. Some high velocity winds occur just above the tropopause; otherwise winds are noticeably absent. Upper boundary layer of the stratosphere is the stratopause.

\subsection{MESOSPHERE}

Above the stratopause is a layer identified by a temperature decrease with altitude (mesosphere). Beginning at an elevation of about $48 \mathrm{~km}$, the decline in temperature continues outward to the mesopause near $80 \mathrm{~km}$. Up to the mesopause, the mixture of gases is about the same as at the surface. For this reason, the lower $80 \mathrm{~km}$ of the atmosphere is termed the homo sphere. Beyond $80 \mathrm{~km}$ altitude, the composition of the air begins to change. Above the homospheric atmosphere, gases tend to stratify on the basis of their molecular weight. This layer is termed the hetero sphere. To a 


\section{International Advanced Research Journal in Science, Engineering and Technology}

Vol. 8, Issue 8, August 2021

DOI: $10.17148 /$ IARJSET.2021.8833

height of $220 \mathrm{~km}$, molecules of nitrogen largely make up the atmosphere. Layers of oxygen, helium and hydrogen exist beyond this height.

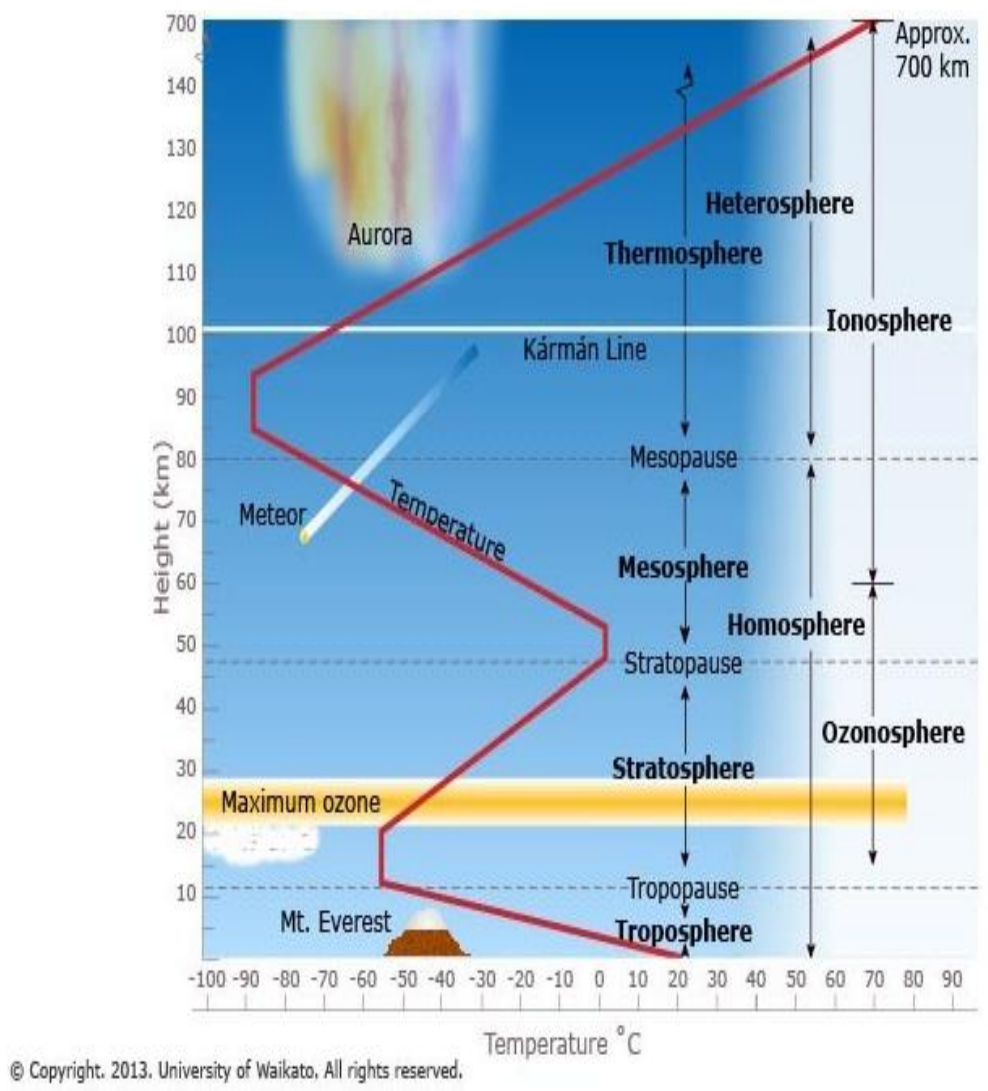

Figure 1: Structure of Atmosphere

\subsection{IONOSPHERE}

The mesosphere merges with a zone called the ionosphere. The incoming solar radiation is able to ionize the neutral particles, so that a region of free electrons, ions and neutral particles exists in the atmosphere. It consists of three major regions: D-region at heights of 60-90 km, E-region from 90-150 km and F-region approximately at 140-230 $\mathrm{km}$ in altitude. The height/altitude varies by means of solar activity, season and geomagnetic activity. During day time, the F-region splits up into F1 and F2 regions and merges during night time. By model simulations an additional layer that occurs above the F2 peak namely the F3 layer was predicted. Its occurrence and variability over Brazilian region was studied.

At altitudes beyond $500 \mathrm{~km}$ the incoming solar radiation begins to interact with the atmosphere. This outer region is where gaseous particles escape the Earth's gravity. Particles are far apart and some of them have a high enough velocity in a direction away from the Earth to escape to space. Above this, to $-1,125 \mathrm{~km}$. atomic oxygen is prevalent. Beyond this layer of atomic oxygen helium is the most common constituent up to - 3,540 km. Still further out, hydrogen atoms predominate. The boundaries among the zones are not clearly defined. The heights represent the altitudes above which a different chemistry predominates.

\subsection{THERMOSPHERE}

Above $80-85 \mathrm{~km}$ (menopauses) is the thermosphere where the neutral gas temperature increases to an altitude of 200 $\mathrm{km}$ and then remains constant to heights exceeding $103 \mathrm{~km}$. The other mal-behavior of the upper thermosphere arises because its thermal conductivity is high and most of the energy absorbed by the gas is removed downwards. During periods of very high solar activity, the Sun emits large amount so ultra-violet radiation and the thermosphere temperature reaches $2200 \mathrm{~K}$. But at the minima of solar activity, no part of the atmosphere exceeds $750 \mathrm{~K}$.

In the lower thermosphere, i.e. below $130 \mathrm{~km}$, heat is transported down to the mesopause by convection. In the upper thermosphere $(130-180 \mathrm{~km})$ heat is transported down to lower levels by conduction resulting in an isothermal region beyond about $500 \mathrm{~km}$. The thermo pause is the point of transition to a more or fewer isothermal summary. The region above $500 \mathrm{~km}$ is known as exosphere. 


\title{
International Advanced Research Journal in Science, Engineering and Technology
}

\author{
Vol. 8, Issue 8, August 2021
}

\section{DOI: $10.17148 /$ IARJSET.2021.8833}

\section{IONOSPHERIC VARIATIONS OVER INDIAN LOW LATITUDES}

The Earth's ionosphere demonstrates complex variabilities with varying spatial and temporal scales. The influencing factors for the ionospheric variabilities are (a) solar ionizing flux, (b) neutral dynamics and electrodynamics, and (c) solar wind conditions. The solar flux, which varies with the 11-year solar cycle, quasi 27-day rotation of the sun, day-to-day and even shorter timescales, has direct control on the plasma density in the ionosphere. The ionosphere is too controlled by the solar zenith angle, manifesting diurnal, annual and semiannual variations. Solar flux induced spatial and temporal variations in the neutral atmosphere lead to the thermospheric wind and electric field. In the low latitudes, the thermospheric wind and electric field, in conjunction with Earth's magnetic field, play an important role in the redistribution of plasma. In the recent past, it has also been recognized that significant variations in ionospheric parameters are governed by lower-atmospheric processes through complex coupling processes in the middle atmosphere.

With regard to the low-latitude ionosphere, variabilities in the F- region have been given special attention due to their direct effects on communication / navigation systems. A large number of observational and modeling studies have been made to understand $F$ region parameters, such as the critical frequency of the F2 layer, foF 2 and the corresponding height, hmF2, in terms of variabilities in solar flux, magnetic field, neutral dynamical / electro dynamical parameters. These studies have provided important inputs to the development of the International Reference Ionosphere (IRI) model, which is widely used by the autonomy community across the world.

\section{CONCLUDING REMARKS:}

Many issues concerning the evolution of solar activity and its impact on Martian volatiles have been answered successfully in the past decade and given the fact that the equatorial/low-latitude ionosphere is highly variable both spatially (both along longitude and latitude) and temporally, and with solar and geomagnetic activity, observations have revealed significant departure from the IRI model. With regard to the Indian sector, although some interesting studies addressing local time, seasonal and solar activity dependence of FoF2 and hmF2 have been made based on observations made from the magnetic equator and from locations close to or beyond the equatorial ionization anomaly crest.

\section{REFERENCES:}

1. Mendillo, M., Schatten, K., Influence of solar sector boundaries on ionospheric variability, Journal of Geophysical Research 88, $9145-9153,1983$. 2. AK. Patra et al., Ionospheric variability over Indian low latitude linked with the 2009 sudden stratospheric warming, vol.27, issue 23 , pp.3-14, 2009.

3. Anju Nagar et al., Day-to-Day Variability of Low Latitude F-Region Ionosphere During Low Solar Activity, International Journal of Astrophysics and Space Science, vol. 3, issue 3, pp.30-41, 2015.

4. A.B. Adel, "Low solar activity variability and IRI 2007 predictability equatorial Africa GPS TEC", Adv. Space Res., vol.49, no. 2, pp. 316-326, 2012.

5. B.O. Adebesin, “ On the ionospheric variability of critical frequency along the equator anomaly trough ad plausible role of vertical EXB drift”, J. Life physical sciences, vol. 5, no. 1, pp. 37-51, 2014.

6. C.T. Russell, and R.L.Mcpherron, "Semiannual variation of geomagnetic activity", J. Geophys. Res., vol. 78, no. 1, 1973, pp. 92-108.

7. D.S.V.V.D. Prasad, S.N.V.S. Prasad, J. Vara Prasad, N.S.M.P. Lathadevi and P.V.S. Rama Rao, "Diurnal and seasonal variations in h'f and foF2 over low and mid latitude stations - A comparative study", Indian Journal of Physics, vol. 84, no. 4, 2010, pp. 345-358.

8. Geeta Khoobchandani et al., Variability of foF2 at Low Latitude during High, Moderate and Low Solar Activity, International Journal of Engineering Trends and Technology (IJETT), Volume-44, Number-2, 2016.

9. Ioanna Tsagouri et al., Solar activity impact on the Earth's upper atmosphere, vol.3, issue 1, pp.135-146, 2013.

10. Ishii, Variability of the ionosphere, J. Atmos. Sol-Terr. Phy., vol. 62, pp.685-693, 2015.

11. P. Pavan Chaitanya et al., Ionospheric variations over Indian low latitudes close to the equator and comparison with IRI-2012, vol.13, issue 4, pp.34-56, 2015.

12. Y.T. Chouand C.C. Lee, "Ionospheric variability at Taiwan low latitude station: Comparison between observations and IRI 2001 model", Adv. Space Res., vol. 42, no. 18, pp. 673-681, 2008.

13. S.A. Pulinets, and J.Y. Liu, "Ionospheric variability unrelated to solar and geomagnetic activity", Adv. Space Res., vol. 34, no. 9, pp. 1926-1933, 2004.

14. Rush, C.M., An ionospheric network for use in short-term propagation predictions, Telecommunication Journal 43 (VIII), $544,1976$.

15. Ishii, Variability of the ionosphere, J. Atmos. Sol-Terr. Phy., vol. 62, pp.685-693, 2015.

16. J.R. Dudeney, "The accuracy of simple methods for determining the height of the maximum electron concentration of the F2-layer form scaled ionospheric characteristics", J. Atmos. Terr. Phys., vol. 45, pp. 629-640.

17. Anupama C.; Thilakam M. R.. "Designing and Evaluating the Performance Solar Powered Iron Box". International Research Journal on Advanced Science Hub, 3, 1, 2021, 1-4. doi: 10.47392/irjash.2021.001

18. Subramanian C.; Chandru Deva Kannan P.; Karthikeyan L.; Prakashraj G.; Nadaraj P.. "Performance enhancement of Waffles (Appalam) drying using mixed mode solar dryer". International Research Journal on Advanced Science Hub, 3, Special Issue ICEST 1S, 2021, 40-45. doi: 10.47392/irjash.2021.018 